\title{
Uma história das práticas alimentares de trabalhadores paulistanos em dois momentos do século $\mathrm{XX}^{\star}$
}

\section{A history of practices in nourishment among workers in São Paulo city in two moments of the $20^{\text {th }}$ century}

JAIME RODRIGUES Departamento de História. Escola de Filosofia, Letras e Ciências Humanas Universidade Federal de São Paulo/UNIFESP Estrada Caminho Velho, 333. CEP 07252-312 Guarulhos. SP. Brasil jaimerod@uol.com.br

RESUMO A partir de uma discussão sobre estudos que lidaram com os temas alimentares nas Ciências Humanas, este artigo aponta as possibilidades das Pesquisas de Padrão de Vida como fontes para uma história social da alimentação entre trabalhadores que viviam em São Paulo durante a primeira metade do século XX. Apresento os métodos de aplicação, as intenções dessas pesquisas e o perfil das famílias. Em seguida, os produtos e as quantidades consumidas pelas famílias são analisados em temporali-

\footnotetext{
* Artigo recebido em: 10/06/2011. Autor convidado.
} 
dades distintas, tentando verificar o impacto da industrialização, da renda e da propaganda.

Palavras-chave história da alimentação, pesquisas de padrão de vida, história social

ABSTRACT Based on studies about food issues in the Humanities, this article indicates the possibilities of the Living Standards Research as sources for a social history of nourishment between workers living in Sao Paulo during the first half of the $20^{\text {th }}$ century. I present the methods of application, the intentions of this research and the profile of families analyzed. After, I analyze the products and quantities consumed by families in different times, trying to understand the impact of industrialization, wage income and advertisement.

Keywords history of nourishment, living standards research, social history

\section{Estudos e questões}

No campo das Ciências Sociais, autores do porte de Josué de Castro, Luís da Câmara Cascudo e Gilberto Freyre debruçaram-se longamente sobre o tema da alimentação. ${ }^{1}$ Porém, o mesmo interesse não ecoou com força igual entre os historiadores contemporâneos. Ainda hoje, a alimentação é um objeto historiográfico relativamente limitado no Brasil, como reconheceram alguns dos poucos estudiosos recentes do assunto. ${ }^{2}$

Ao proceder a um balanço recente, focado em São Paulo e nos paradoxos de sua narrativa histórica, pude identificar um longo intervalo de quase completa ausência de estudos sobre a temática. Pouca produção historiográfica veio à luz entre o já cinquentenário interesse expressado por Sérgio Buarque de Holanda em Caminhos e fronteiras (1957) quanto à assimilação dos hábitos (alimentares, inclusive) dos indígenas pelos colonizadores portugueses para sobreviver na terra, de um lado, e a era da metropolização, mais precisamente o século XX, ${ }^{3}$ de outro. Talvez parte do reduzido interesse dos historiadores do tema pelo século passado ainda possa ser creditado à política de recolhimento da documentação aos arquivos históricos, mas isso não explica tudo.

1 CASTRO, Josué de. Geografia da fome. Rio de Janeiro: O Cruzeiro, 1946; CASCUDO, Luis da Câmara. Cozinha africana no Brasil. Luanda: Museu de Angola, 1964; CASCUDO, Luis da Câmara. História da alimentação no Brasil. São Paulo: Cia. Ed. Nacional, 1967; FREYRE, Gilberto. Nordeste aspectos da influencia da cana sobre a vida e a paisagem do nordeste do Brasil. Rio de Janeiro: José Olympio, 1951.

2 SANTOS, Carlos Alberto Antunes dos. Por uma história da alimentação. História: Questões \& Debates, Curitiba, p.26-27: 1997; CARNEIRO, Henrique e MENESES, Ulpiano Toledo Bezerra de. A história da alimentação: balizas historiográficas. Anais do Museu Paulista, São Paulo, v.5, p.9-91, jan./dez.1997; CARNEIRO, Henrique. Comida e sociedade: uma história da alimentação. $2^{a}$.ed. Rio de Janeiro: Campus, 2003.

3 RODRIGUES, Jaime. Por uma história da alimentação na cidade de São Paulo (décadas de 1920 a 1950). Revista de Estudios Sociales, Santiago, v.33, p.118-128, 2009. 
Na primeira metade do século XX, a capital paulista tornou-se uma imensa metrópole multicultural, onde se reuniram numerosas comunidades estrangeiras e de outros estados do Brasil, em meio às quais podiam ser encontrados hábitos e práticas alimentares os mais variados. Apesar desse potencial, não aflorou entre os historiadores um interesse especial em abordar a história da alimentação, ainda que haja um vínculo evidente entre alimentação e saúde pública e este último tema tenha sido objeto de uma vasta produção historiográfica centrada, em particular, nas instituições públicas de regulamentação e intervenção social e nas práticas populares - autônomas ou em reação às políticas emanadas do poder público. ${ }^{4}$

Estudos mais recentes destacaram as transformações pelas quais passou o ambiente doméstico, sobretudo o espaço da cozinha. Boa parte dessas transformações se deu pari passu à industrialização, tendo os estudiosos desse processo trabalhado no interior do recorte temporal que vai de fins do século XIX às primeiras décadas do século XX. João Máximo da Silva, por exemplo, ressaltou que a organização das cozinhas ganhou mais importância no Brasil a partir da década de 1930, tendo por marco o I Congresso de Habitação. Naquele evento, o parâmetro

era justamente o debate da arquitetura européia, sobre a intervenção na vida das classes trabalhadoras por intermédio da construção de moradias. Mas, antes disso, as preocupações com a cozinha e o trabalho doméstico foram introduzidas com a medicina sanitária e a oferta de gás e eletricidade para uso doméstico no início do século XX. ${ }^{5}$

Outro foco de interesse refere-se à cultura visual, especialmente à propaganda. ${ }^{6}$ Consciente das tentações visuais produzidas a partir da veiculação de propagandas em diferentes mídias, a nascente indústria alimentícia investiu maciçamente em divulgação. Os fabricantes empenharam-se em várias frentes e as campanhas publicitárias em mídia impressa, como as de Maizena até os anos 1950, são exemplares:

4 Entre muitos outros estudos, podem ser citados os de ROCHA, Heloísa Helena Pimenta. A higienização dos costumes: educação escolar e saúde no projeto do Instituto de Higyene de São Paulo (1918-1925). Campinas: Mercado de Letras; São Paulo: FAPESP, 2004; RESENDE, Eliana Almeida de S. Imagens da cidade, clichês em foco: São Paulo e Lisboa, 1900-1928. Campinas: IFCH/UNICAMP; CAMPOS, Cristina. São Paulo pela lente da higiene: as propostas de Geraldo Horácio de Paula Souza para a cidade, 1925-1945. São Paulo: Rima/FAPESP, 2001; SILVA, James Roberto. Doença, fotografia e representação: revistas médicas em São Paulo e Paris, 18691925. São Paulo: Edusp, 2009.

5 SILVA, João Luiz Máximo da. Cozinha modelo: o impacto do gás e da eletricidade na casa paulistana (1870-1930). São Paulo: Edusp, 2008, p.96-97. Ver também CARVALHO, Vânia Carneiro de. Gênero e artefato: o sistema doméstico na perspectiva da cultura material (São Paulo, 1870-1920). São Paulo: Edusp/FAPESP, 2008. Sobre o uso de apetrechos de cozinha na Argentina, ver DE LAZZARI, Gastón. Carbón, kerosene, gas. Artefactos de cocina en la publicidad gráfica argentina (1940/1970). Revista de Ciencias Humanas y Sociales, Maracaibo, v.21, n.46, p.39-54, jan. 2005.

6 Ver, entre outros, BARBOSA, Lívia. Feijão com arroz e arroz com feijão: o Brasil no prato dos brasileiros. Horizontes Antropológicos, Porto Alegre, v.13, n.28: dez.2007. Disponível em http://www.scielo.br/scielo.php?script=sci_ arttext\&pid=S0104-71832007000200005\&lng=pt\&nrm =iso (acesso em 30 maio 2011). 
O produto foi representado no centro da cena, na forma de pudim sobre o prato, havendo ao seu redor crianças de diversas nacionalidades ou etnias (...). Nesse exemplo, as gerações foram identificadas a toda a humanidade, como se o artigo agradasse às pessoas dos mais diversos lugares do mundo e isso fosse um motivo a mais para ser adotado pelos consumidores brasileiros. ${ }^{7}$

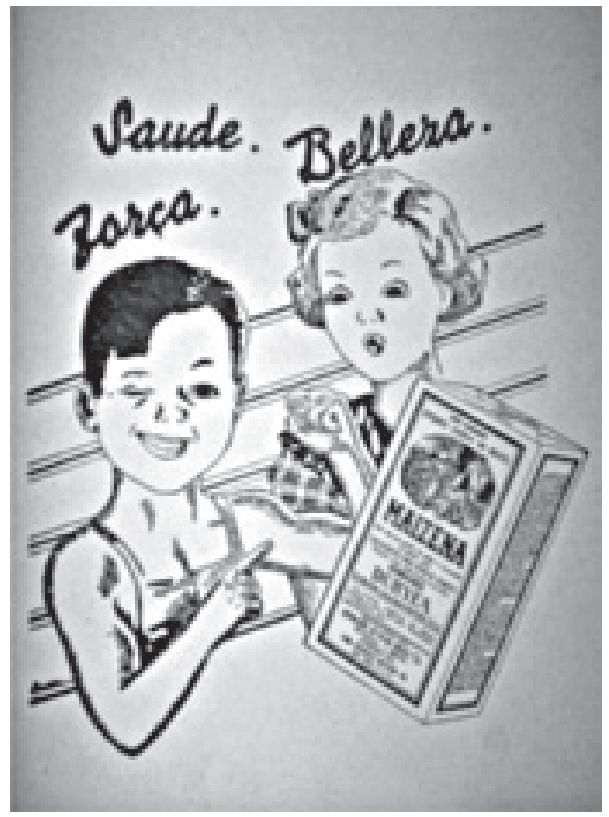

Figura 1

Publicada em 1938 e nos anos seguintes, esta imagem faz alusão ao próprio subtítulo da revista onde foi publicada. Meninos e meninas poderiam consumir o produto - portanto, não havia distinção entre sexos, embora o efeito causado fosse diferente. Para meninos, o produto traria "saúde e força", palavras diagramadas sobre a cabeça do menino que flexiona o bíceps diante de uma menina visivelmente impressionada. Para ela, a "beleza" deveria ser mais importante, talvez tanto quanto encontrar alguém forte e saudável do sexo oposto, quando chegasse a hora.

Fonte: Viver! Mensário de força, saúde e beleza, v.1, n.4, p.59, 15 out./15 nov.1938.

Além da mídia impressa, a partir de 1950 havia no Brasil a novidade representada pela televisão. Com o advento televisivo, produtos alimentícios compravam espaço de publicidade não apenas nos intervalos comerciais: as marcas também passaram a ser associadas aos títulos dos programas, como nas Sabatinas Maizena e na Gincana Kibon (1955), transmitidas pela TV Tupi dos primeiros tempos.

Todavia, o impacto da industrialização sobre as práticas alimentares entre os trabalhadores de São Paulo nas décadas de 1930 a 1960 poder

7 BRITES, Olga. Imagens da infância: São Paulo e Rio de Janeiro, 1930 a 1950. São Paulo: PUCSP, 1999, p. 230. (História, Tese de Doutorado) 
ser superestimado se nos prendermos exclusivamente ao que sugere a propaganda de alimentos ou de equipamentos de cozinha. Para embasar essa afirmação e sugerir alguns cuidados aos historiadores interessados no tema, apresentarei alguns dados referentes às Pesquisas de Padrão de Vida (PPVs) aplicadas entre famílias de trabalhadores em dois momentos desse intervalo temporal: 1937 e $1963 .^{8}$

\section{As Pesquisas de Padrão de Vida}

Antes de prosseguir, cabe uma explicação acerca das PPVs. Tratava-se de amplas coletas de dados cujo objetivo oficial e declarado era subsidiar a definição do valor do salário mínimo, instituído no Brasil em meados da década de 1930.9

Uma vez escolhido o universo da amostragem, as famílias de trabaIhadores recebiam uma caderneta, e nela a mulher/mãe deveria anotar diariamente os gastos feitos na manutenção da casa e de seus moradores. Além de instruir acerca do preenchimento da caderneta, os pesquisadores tinham que convencer o "indicado" (o homem, chefe de família e principal provedor do lar) ou sua mulher (na maior parte das vezes esta última) a responder um questionário bastante detalhado sobre os itens de despesas domésticas. O principal interesse voltava-se aos custos mais vultosos e relativamente fixos - como aluguel, água, luz, combustíveis, alimentação, artigos de limpeza e vestuário -, mas os pesquisadores também queriam saber o quanto as famílias gastavam com o pagamento de dívidas e crediários, educação formal, remédios, assistência médica e criação de animais. Um terceiro bloco de despesas referia-se à vida fora da casa: gastos com bonde ou outros meios de transporte, lazer e pagamentos a associações.

A permanência do item "despesas com criação" indica que a metrópole paulistana estava em pleno processo de formação, nela ainda havendo moradias com terrenos espaçosos o suficiente para abrigarem cercados onde eram criados galinhas ou outros animais de pequeno porte - isso ao menos até que as geladeiras se popularizassem entre as famílias brasileiras com membros numerosos. Pelo menos até a década de 1970, havia galinheiros em algumas casas e também era comum a existência das "granjas", nome

8 Para as décadas posteriores, ver MONDINI, Lenise; MONTEIRO, Carlos A. Mudanças no padrão de alimentação da população urbana brasileira (1962-1988). Revista de Saúde Pública, São Paulo, v.28, n.6, dez. 1994. Disponível em http://www.scielo.br/scielo.php?script=sci_arttext\&pid=S0034-89101994000600007\&lng=pt\&nrm=iso (acesso em 30 mar.2011).

9 Cf. Lei no 185, de 14 jan.1936. Disponível em http://www6.senado.gov.br/legislacao/ListaPublicacoes.action?id= 21191. Regulamentada pelos decretos-leis n 399, de abril de 1938 e n 2.162 , de $1^{\circ}$ de maio de 1940 . Disponíveis em http://www6.senado.gov.br/legislacao/ListaPublicacoes.action?id=12746\&tipoDocumento=DEL\&tipoTexto= PUB e http://www6.senado.gov.br/legislacao/ListaPublicacoes.action?id=37717\&tipoDocumento=DEL\&tipoText $\mathrm{O}=\mathrm{P} \cup \mathrm{B}$. 
dado aos estabelecimentos de bairros onde se fazia o comércio de animais vivos, que ali eram abatidos e levados para casa, onde eram depenados (ou despelados, conforme o caso) e cozidos. Frangos e coelhos eram comprados nessas granjas, sendo lavados e escaldados no tanque de lavar roupas dos quintais domésticos. A prática deveria ser comum, a julgar pelas edições do início da década de 1960 do popular livro de receitas Dona Benta - Comer Bem, que incluíam, nas instruções de preparo de frangos, ensinamentos precisos sobre como retirar com eficiência as penas da ave.

O questionário da pesquisa de padrão de vida inquiria os nomes dos membros da família, quantos eram, de que idade, cor, nacionalidade ou naturalidade, escolaridade e renda, além de interessar-se pela condição geral de higiene da moradia. Os tipos de dados colhidos revelam que, para além da fixação do valor do salário mínimo, o Estado tinha outros interesses, censitários e sociológicos, ao aplicar tais pesquisas.

O item "renda" era decisivo. Anotava-se o valor dos salários dos membros da família, dos parentes ou estranhos que vivessem temporariamente na moradia, a renda obtida com pensionistas, os donativos recebidos de parentes ou amigos e as dívidas contraídas. Via de regra, apontavam-se nas cadernetas os ordenados de cada integrante do grupo familiar. Mas a suposição de que moradores "estranhos" vivendo no domicílio também ajudavam a compor a renda indica a persistência do "agregado" na composição da renda mediante aluguel ou sublocação de espaços na casa uma pensão, um cortiço ou apenas uma casa na qual os proprietários ou inquilinos eventualmente alugassem um ou mais cômodos para pagar as despesas, em situações como o desemprego do "chefe da família".

Nesse sentido, a habitação popular entre as décadas de 1930 e 1960 se transformara em relação ao que fora em fins do século XIX, mas ainda guardava certa semelhança com a São Paulo do início da industrialização. Uma comissão nomeada para fiscalizar a higiene das moradias no distrito de Santa Efigênia em 1893 categorizou as habitações em "cortiços (habitações acessadas através de um corredor que leva ao interior da quadra), casinhas (prédios independentes com entrada pela via pública), hotel-cortiço (usado especialmente por operários solteiros que dividiam vagas em quartos) e prédios de sobrados (construções adaptadas e subdivididas)". Os técnicos dessa comissão apontaram, ainda, a existência de dois tipos de submoradias em condições ainda mais preocupantes: "as vendas com aposentos alugados nos fundos do comércio, e os cortiços improvisados, de tábuas ou de zinco, nos fundos de depósitos comerciais de madeira e materiais de construção, ou nos canteiros de obras, estábulos ou cocheiras". ${ }^{10}$

10 Ver RODRIGUES, Jaime. Da "chaga oculta" aos dormitórios suburbanos: notas sobre higiene e habitação operária na São Paulo de fins do século XIX. In: CORDEIRO, Simone Lucena. (org.) Os cortiços de Santa Ifigênia: sanitarismo e urbanização. São Paulo: IMESP/Arquivo Público do Estado de São Paulo, 2010, p.82. 
A escolha das famílias e das moradias pautava-se pela atividade dos "indicados", mas as cadernetas remanescentes das PPVs também indicam as possibilidades de inserção das mulheres no mundo do trabalho, exercido na casa e fora dela. Entre outras ocupações, são mencionadas as de costureira, lavadeira, operária, empregada doméstica, bordadeira, feirante, bancária, cabeleireira, escrituraria e passadeira.

Na PPV de 1937, os questionários não assinalaram endereços ou áreas da cidade onde a pesquisa foi aplicada. Já para a de 1963, restaram questionários e cadernetas dos bairros de Aclimação, Bela Vista, Bom Retiro, Casa Verde, Cidade Ademar, Itaim, Jabaquara, Liberdade, Pinheiros, Santana, Saúde, Tucuruvi, Vila Clementino e Vila Guilherme.

A aplicação da PPV de 1937 foi coordenada por Samuel Lowrie, professor da Escola Livre de Sociologia e Política de São Paulo e pioneiro da Sociologia Aplicada no Brasil. Essa pesquisa serviu de base para a elaboração do primeiro índice de custo de vida da Prefeitura de São Paulo.11 Já a PPV de 1963 foi coordenada pelo economista uruguaio radicado no Brasil Authos Pagano, também no âmbito da prefeitura paulistana, sendo ambas levadas a cabo pela Divisão de Estatística e Documentação Social do Departamento de Cultura, então dirigida por Pagano. ${ }^{12}$

\section{Práticas alimentares: produtos e consumo}

Como avaliar o consumo popular de alimentos em São Paulo em momentos distintos do século XX? Além da disponibilidade dos produtos no comércio e do acesso às mídias, é preciso considerar, principalmente, o fator "renda" nessa avaliação.

Nas Pesquisas de Padrão de Vida, a maior parte das anotações feitas nas cadernetas referia-se aos gastos diários com alimentação. Assim, revisitei essas anotações em busca de dados que me permitissem comparar dois momentos - 1937 e 1963 - no interior de uma amostragem homogênea no quesito "renda". Embora não se possa perder de vista as transformações pelas quais a cidade passou no intervalo que separa as duas pesquisas, é possível comparar os padrões de consumo alimentar de trabalhadores com rendas semelhantes e verificar o que, afinal, essas famílias comiam.

As práticas alimentares seriam, assim, informadas pela origem dos grupos sociais - se nacionais ou estrangeiros, por exemplo - e pela disponibilidade de bens de consumo no sistema de abastecimento alimentar da cidade.

Infelizmente, nas 8 cadernetas restantes da PPV Lowrie, de 1937, não foram registradas informações sobre o número de membros das famílias,

11 Lowrie utilizou os dados para escrever o artigo LOWRIE. Padrão de vida dos operários da limpeza pública de São Paulo. Revista do Arquivo Municipal de São Paulo, v.51, out.1938.

12 Ver http://www.apaacultural.org.br/authospagano/espaco.php (acesso em 25 maio 2011). 
como podemos encontrar nas 34 cadernetas restantes da PPV Pagano, de 1963. Por isso, estabelecer uma média de consumo alimentar per capita torna-se inviável. Mas minha intenção é identificar permanências e preferências entre os consumidores, bem como avaliar as transformações no que se refere à disponibilidade e compra de produtos alimentícios industrializados. O ponto de partida para isso não são as evidências representadas pela propaganda ou pelos dados de produção, mas sim o consumo anotado pelas famílias nas cadernetas das PPVs.

Em 1937 a presença de estrangeiros na população de São Paulo era bem mais sensível do que em 1963. Dados dos censos revelam que, em 1940, o estado tinha 7.180.316 habitantes, sendo 6.363.320 brasileiros natos (88\%), 5.613 .781 nascidos no estado (78\%); italianos eram 213.091 (3\%). ${ }^{13}$ Em 1960, eram 12.823.806 habitantes, sendo 12.030 .025 brasileiros natos (94\%), 10.161.742 dos quais nascidos no próprio estado (79\%); italianos totalizavam $136.332(0,1 \%)$ moradores. ${ }^{14}$

Outra diferença está na quantidade de itens consumidos pelas famílias de trabalhadores, bem maior e mais diversa na pesquisa feita em 1963, sinal da oferta ampliada de produtos alimentícios na rede comercial de abastecimento urbano, muitos deles provenientes das indústrias especializadas.

A expectativa de consumo alimentar me fazia supor que produtos mais comumente ligados aos hábitos de italianos (massas, por exemplo) aparecessem com maior frequência na pesquisa de 1937. Em 1940, a partir dos estudos de Lowrie e de outras experiências com inquéritos alimentares, Oscar Egídio de Araújo ${ }^{15}$ investigou os problemas da alimentação dos operários em São Paulo. Em suas investigações, ele atentou para o peso do fator nacionalidade nos comportamentos alimentares. Constatando que a população da cidade era composta por grupos de origens nacionais bastante diferenciadas, Araújo percebeu as diferenças que isso introduzia no consumo, notando a importância desse fator e a complexidade da questão na capital paulista. De acordo com ele, era possível identificar práticas alimentares diferentes conforme os grupos nacionais reunidos em São Paulo na segunda metade da década de 1930. Brasileiros consumiam

13 IBGE. Recenseamento Geral do Brasil (10 de setembro de 1940). Série Regional, parte VII. São Paulo. Rio de Janeiro: IBGE 1950, t I. p.1, 7. Disponível em http://biblioteca.ibge.gov.br/visualizacao/monografias/GEBIS\%20 -\%20RJ/CD1940/Censo\%20Demografico\%201940_pt XVII_t1_SP.pdf (acesso em 25 maio 2011).

14 IBGE. Censo Demográfico de 1960. São Paulo. Iñ: VII Receñseamento Geral do Brasil. Série Regional. Rio de Janeiro: IBGE, s/d. v. 1, t. XIII, p.10, 12, 14. Disponível em http://biblioteca.ibge.gov.br/visualizacao/monografias/ GEBIS\%20-\%20RJ/CD1960/CD_1960_SP.pdf (acesso em 25 maio 2011.

15 Oscar Egídio de Araújo (1908-1973), "formado em direito pela USP, foi professor de estatística e de pesquisas sociais da Escola de Serviço Social e assistente de métodos e pesquisas sociais da Escola Livre de Sociologia e Política de São Paulo. Foi diretor da Divisão de Pesquisas Sociais do SESI". Cf. PINHEIRO FILHO, Fernando Antonio e MICELI, Sergio. Entrevista com Mário Wagner Vieira da Cunha. Tempo Social, São Paulo, v.20, n.2, nov.2008. (disponivel em http://www.scielo.br/scielo.php?script=sci arttext\&pid=S0103-20702008000200013\&lng=en\&nr m=iso (acesso em 30 maio 2011). Como técnico de estatística da Divisão de Estatística e Documentação Social do Departamento de Cultura da Prefeitura de São Paulo, ele coordenou a aplicação de uma PPV na cidade entre 1951 e 1952. Lecionou, ainda, na Escola de Enfermagem do Hospital São Paulo. 
mais açúcar, arroz e feijão, e menos pão, batata e leite. Portugueses e italianos aproximavam-se de brasileiros na média de consumo da maior parte dos alimentos, mas os primeiros destacavam-se no consumo de batata, bacalhau e farinha de trigo, enquanto os segundos compravam mais macarrão, com pouco consumo de batata e peixe. Espanhóis, por sua vez, destacavam-se pelo consumo de pão, gordura, tomate, batata e leite associados a pouca farinha de trigo, enquanto lituanos eram grandes consumidores de carne bovina, batatas, peixe, farinha de trigo, queijo e manteiga, pouco consumindo arroz, feijão e macarrão. ${ }^{16}$

O macarrão foi anotado como produto consumido entre 7 das 8 famílias cujas cadernetas foram conservadas a partir da Pesquisa Lowrie. ${ }^{17}$ Arroz e feijão, itens básicos do cardápio dos brasileiros, foram assinalados nas mesmas 7 cadernetas, todavia em quantidades bem maiores do que as de macarrão. ${ }^{18}$ Assim, pela simples observação do tipo de alimento consumido, não se pode deduzir a origem nacional das famílias e extrair daí tradições alimentares seguidas à risca na nova terra.

Tabela 1 - PPV LOWRIE

\begin{tabular}{c|c|c}
\hline$N^{0}$ do caso e período & Gênero consumido & Unidade e quantidade \\
\hline \multirow{3}{*}{1 [não consta] } & Arroz & $2 \mathrm{~kg}$ \\
& Feijão & $2 \mathrm{~kg}$ \\
& Macarrão & $1 \mathrm{~kg}$ \\
\hline \multirow{3}{*}{533 (4 maio a 4 jun.1937) } & Arroz & $26 \mathrm{~kg}$ \\
& Feijão & $22 \mathrm{~kg}$ \\
& Macarrão & $2 \mathrm{~kg}$ \\
\hline \multirow{2}{*}{552 (17 abr. a 10 maio 1937) } & Arroz & $29 \mathrm{~kg}$ \\
& Feijão & $9 \mathrm{~kg}$ \\
& Macarrão & $2 \mathrm{~kg}$ \\
\hline \multirow{2}{*}{603 (28 abr. a 28 maio.1937) } & Arroz & $9 \mathrm{~kg}$ \\
& Feijão & $12 \mathrm{~kg}$ \\
& Macarrão & $3 \mathrm{~kg}$ \\
\hline \multirow{2}{*}{1504 (4 jan a 2 fev.1937) } & Arroz & $7 \mathrm{~kg}$ \\
& Feijão & $7 \mathrm{~kg}$ \\
& Macarrão & $2 \mathrm{~kg}$ \\
\hline \multirow{2}{*}{1622 (5 jan. a 4 fev.1937) } & Arroz & $10 \mathrm{~kg}$ \\
& Feijão & $6 \mathrm{~kg}$ \\
& Macarrão & $10 \mathrm{~kg}$ \\
\hline \multirow{2}{*}{1680 (8 jan a 6 fev.1937) } & Arroz & $6 \mathrm{~kg}$ \\
& Feijão & $1 / 2 \mathrm{~kg}$ \\
& Macarrão & $1 \mathrm{~kg}$ \\
\hline
\end{tabular}

16 ARAÚJO, Oscar Egídio de. A alimentação da classe obreira de São Paulo. Revista do Arquivo Municipal de São Paulo, v.69, p.99-101, ago.1940.

17 As cadernetas e os demais documentos referentes às Pesquisas de Padrão de Vida encontram-se no Arquivo Histórico Municipal de São Paulo, fundo Prefeitura Municipal, grupo Departamento de Cultura, subgrupo Divisão de Estatística e Documentação Social.

18 Uma única família não consumiu nenhum dos três tipos de alimentos, Cf. PPV Lowrie, caso 1044 (anotações em 29 abr.1937). 
O macarrão, consumido em quantidades bem menores que os demais itens básicos do prato a cada refeição, era um produto industrializado, comprado a granel ou em embalagens com peso definido. Se seu preço era maior, isso poderia ajudar a explicar o menor consumo. Mas as cadernetas podem conter pistas de que a massa fosse feita na própria casa. Para isso, seria preciso que as famílias consumissem farinha e ovos mais abundantemente. Vejamos o que as anotações informam a esse respeito.

Farinha aparece como item de consumo alimentar entre quatro famílias. Apenas uma delas comprou uma quantidade relativamente grande $(7 \mathrm{~kg})$ e as demais compraram apenas $1 \mathrm{~kg}$ ou não especificaram os volumes. Ovos, por sua vez, apareceram como item em três cadernetas, variando entre uma e duas dúzias. Porém, seria preciso descobrir se esse produto era mais comumente adquirido em mercados ou mercearias ou se advinha da criação de galinhas nos quintais das próprias casas - e, neste caso, não seria assinalado como despesa nas cadernetas das PPVs.

Partindo destas observações, fica claro que o consumo de macarrão industrializado ou feito em casa não superava o de arroz e feijão, na amostragem de 1937. Isso, porém, não significa que os italianos tenham deixado menos marcas do que os nacionais na definição de cardápios no dia a dia de famílias trabalhadoras na São Paulo da segunda metade dos anos 1930. Os casos, pouco numerosos, não permitem conclusão tão abrangente, e a influência desse grupo estrangeiro sobre as formas da alimentação do conjunto dos moradores da cidade deixou marcas que as evidências aqui utilizadas não deixam entrever.

De acordo com Rosa Belluzzo, ao mesmo tempo em que aderiram às "práticas alimentares paulistas" - ao consumirem carne de porcos e frangos, por exemplo, ao que poderíamos acrescentar arroz e feijão -, os italianos introduziram entre os paulistas o cultivo e o hábito consumir verduras. ${ }^{19}$

Lidando com fontes como as que venho mencionando, dentre outras, os estudos acerca das práticas, dos comportamentos e dos hábitos alimentares das comunidades de estrangeiros e seus descendentes na cidade poderão ser aprofundados. Evidentemente, não se trata aqui de uma discussão sobre gastronomia, entendida como "arte de cozinhar proporcionando prazer. Influi sobre a imaginação e o espírito humano, sendo seus conhecimentos necessários para o convívio social” ${ }^{20}$ Se fosse o caso, talvez devêssemos lidar com uma concepção de gastronomia não apenas como arte de cozinhar e prazer de comer,

19 BELLUZZO, Rosa. São Paulo: memória e sabor. São Paulo: Ed. da Unesp, 2008, p.61.

20 PHILIPPI, Sonia Tucunduva e COLUCCI, Ana Carolina Almada. São Paulo. In: FISBERG, Mauro et alii. Um, dois, feijão com arroz: a alimentação no Brasil de norte a sul. São Paulo: Atheneu, 2002, p.211. 
mas também a sua relação com os recursos alimentares disponíveis, pois as condições naturais de vida são extremamente variadas: influência da latitude, natureza dos solos, proximidade do mar, clima etc. ${ }^{21}$

De outro lado, se atentarmos para a adaptação gastronômica dos imigrantes estrangeiros aos produtos disponíveis em São Paulo, veremos que ao longo do processo certamente modificaram-se os hábitos e os comportamentos alimentares tanto dos que chegavam quanto dos moradores da cidade que os recebiam..$^{22}$

De todo modo, não se deve perder de vista que o crescimento de São Paulo a partir de fins do século XIX e início do XX, em razão da presença de imigrantes italianos, ibéricos e asiáticos, mas também de indígenas e descendentes de africanos, foi marcado sobremaneira pela cultura caipira: "portanto, não há dúvida: São Paulo também é interior, também é caipira, mantém hábitos tradicionais; é uma metrópole caipira". ${ }^{23}$

Mas é plausível supor que consumos tão elevados de arroz e feijão tenham uma relação com o preço mais acessível desses alimentos e/ou com a dificuldade de abastecimento de itens como farinha de trigo, sujeita a variações sazonais e circunstanciais. Sinais disso foram os novos ingredientes experimentados durante a Segunda Guerra Mundial na misturas de panificação - sendo clássico o caso do Pão de Guerra.. ${ }^{24}$ Em 1943, foi constituída uma Comissão do Pão de Guerra dos Fundos Universitários, cuja proposta de uma mistura contendo farinha de trigo, leite em pó e fosfato tricálcico, entre outros ingredientes, foi aprovada: "panificou bem e houve aumento do valor nutritivo". ${ }^{25}$ Diferentes misturas foram testadas no preparo

21 ABREU, Edeli Simioni de et alii. Alimentação mundial: uma reflexão sobre a História. Saúde e Sociedade, São Paulo, v.10, n.2, ago./dez.2001. Disponível em <http://www.scielo.br/scielo.php?script=sci_arttext\&pid= S0104-2902001000200002\&lng =pt\&nrm $=$ iso $>$.

22 As adaptações e interações alimentares das comunidades em deslocamento e dos residentes em São Paulo havia mais tempo são um objeto a ser explorado. Marinna Heck e Rosa Belluzzo colheram depoimentos de imigrantes e seus descendentes e, ao menos em um caso, o assunto veio à tona: no registro da fala da Sra. Marisa, lemos que "em casa só ficou um caderno de receitas que foi da minha avó paterna. Não tem só receitas piemontesas. Esse livro é um misto de receitas italianas e americanas, pois meus avós paternos moraram por algum tempo nos Estados Unidos". HECK, Marinna e BELLUZZO, Rosa Cozinha dos imigrantes: memórias \& receitas. São Paulo: DBA/Melhoramentos, 1998, p.39. Existem alguns estudos, por exemplo, sobre a comunidade japonesa, como o de ISHII, Midori. Hábitos alimentares de segmentos populacionais japoneses: histórico da natureza e direção de mudança. São Paulo: FSP/USP, 1986. Para a comunidade italiana, ver OLIVEIRA, Flávia Arlanch Martins de. Padrões alimentares em mudança: a cozinha italiana no interior paulista. Revista Brasileira de História, São Paulo, v.26, n.51, jun. 2006. Disponível em http://www.scielo.br/scielo.php?script=sci arttext\&pid=S0102-01882006000100004\&ln $\mathrm{g}=$ pt\&nrm $=$ iso (acesso em 20 fev.2011).

23 FRANCISCO, Luís Roberto de. A gente paulista e a vida caipira. In: SETÚBAL, Maria Alice. (coord.) Terra Paulista - Modos de vida dos paulistas: identidades, famílias e espaços domésticos. São Paulo: IMESP; CENPEC, 2004, v.2, p.44.

24 Em 1937 - antes, portanto, do início da guerra -, o Decreto n.26 institui o "pão misto", incluindo trigo, milho e raspas de mandioca na mistura. Ver SILVA, Benedito Bruno da. A soja: sua importância na alimentação, seu emprego no pão. São Paulo: Ed. Revista dos Tribunais, 1941, p.9, 97

25 CAMPOS, Franklin A. de Moura. Problemas brasileiros de alimentação. Rio de Janeiro: Serviço de Alimentação da Previdência Social, 1949, p.160-166. 
do pão no contexto da Segunda Guerra Mundial ou às suas vésperas, com ingredientes como a soja e outros. ${ }^{26}$

Do mesmo modo, é plausível que o fator nacionalidade tenha sido superestimado nos estudos sociológicos e que italianos, em uniões matrimoniais onde um dos cônjuges não era oriundi, bem como seus descendentes, nessa altura tivessem se adaptado aos produtos que o comércio de alimentos paulistano era capaz de oferecer aos consumidores. No abastecimento da cidade, arroz e feijão eram oferecidos desde muito tempo.

Vejamos o que ocorreu com o consumo desses três produtos - arroz, feijão e macarrão - em 1963. Dos 34 casos da PPV Pagano, 33 mencionam o consumo de arroz, 31 o de feijão e 32 o de macarrão. Quanto a este último produto, a própria forma de anotar as quantidades consumidas indica o avanço da industrialização, aí incluído o setor de embalagens. Se na pesquisa de 1937 era comum a anotação na caderneta dos quilogramas comprados - sinal de comércio a granel disseminado, com mobiliário apropriado nos armazéns e quitandas para o acondicionamento dos diferentes tipos de produto -, em 1963 a unidade mais comum era o "pacote". Em um dos casos, especificou-se o espaguete e, em outros dois, mencionouse o "macarrãozinho" ou "macarrão para sopa", sempre em quantidades menores, mas denotando a diversificação dos itens industrializados. Nessa pesquisa, também foi mais comum a anotação das marcas - como o macarrão Adria, fabricado no Rio Grande do Sul desde 1951 por uma família de imigrantes italianos. ${ }^{27}$

Diferentemente da PPV Lowrie, na Pagano podemos quantificar o consumo per capita dos produtos, pois as anotações informam o número de membros das famílias pesquisadas.

Tabela 2 - PPV PAGANO

\begin{tabular}{|c|c|c|c|c|}
\hline $\mathrm{N}^{0}$ do caso e período & $\begin{array}{c}\text { Gênero } \\
\text { consumido }\end{array}$ & $\begin{array}{l}\text { Unidade e } \\
\text { quantidade }\end{array}$ & $\begin{array}{l}N^{0} \text { membros } \\
\text { família }\end{array}$ & $\begin{array}{c}\text { Consumo } \\
\text { per capita/mês }\end{array}$ \\
\hline \multirow{3}{*}{101 (02 ago a 02 set.1963) } & Arroz & $15 \mathrm{~kg}$ & 5 & $3 \mathrm{~kg}$ \\
\hline & Feijão & $5 \mathrm{~kg}$ & & $1 \mathrm{~kg}$ \\
\hline & Macarrão & $2 \mathrm{~kg}$ & & $400 \mathrm{~g}$ \\
\hline \multirow{3}{*}{102 (2 ago a 1 set.1963) } & Arroz & $11 \mathrm{~kg}$ & 3 & $3,7 \mathrm{~kg}$ \\
\hline & Feijão & $4 \mathrm{~kg}$ & & $1,4 \mathrm{~kg}$ \\
\hline & Macarrão & $2 \mathrm{~kg}$ & & $700 \mathrm{~g}$ \\
\hline \multirow{3}{*}{103 (5 ago a 4 set.1963) } & Arroz & $14 \mathrm{~kg}$ & 5 & $2,8 \mathrm{~kg}$ \\
\hline & Feijão & $5 \mathrm{~kg}$ & & $1 \mathrm{~kg}$ \\
\hline & Macarrão & $7 \mathrm{~kg}$ & & $1,4 \mathrm{~kg}$ \\
\hline
\end{tabular}

26 SILVA, A soja. Em O problema da carestia do pão em São Paulo, Gustavo Zalecki tratou da mistura do chamado "pão do povo", feito com metade de farinha de trigo e metade de farinha de mandioca. Ver ZALECKI, Gustavo. O problema da carestia do pão em São Paulo. Revista do Arquivo Municipal de São Paulo, v.44, p.42-44, fev.1938.

27 Cf. http://www.adria.com.br/empresa/ (acesso em 22 abr.2011). 
Uma história das práticas alimentares de trabalhadores paulistanos em dois momentos do século XX

\begin{tabular}{|c|c|c|c|c|}
\hline $\mathrm{N}^{0}$ do caso e período & $\begin{array}{c}\text { Gênero } \\
\text { consumido }\end{array}$ & $\begin{array}{l}\text { Unidade e } \\
\text { quantidade }\end{array}$ & $\begin{array}{l}N^{0} \text { membros } \\
\text { família }\end{array}$ & $\begin{array}{c}\text { Consumo } \\
\text { per capita/mês }\end{array}$ \\
\hline \multirow{3}{*}{104 (6 ago a 5 set.1963) } & Arroz & $29 \mathrm{~kg}$ & \multirow[t]{3}{*}{7} & $4,150 \mathrm{~kg}$ \\
\hline & Feijão & $15 \mathrm{~kg}$ & & $2,150 \mathrm{~kg}$ \\
\hline & Macarrão & $7 \mathrm{~kg}$ & & $1 \mathrm{~kg}$ \\
\hline \multirow{3}{*}{105 (s/d) } & Arroz & $20 \mathrm{~kg}$ & \multirow[t]{3}{*}{5} & $4 \mathrm{~kg}$ \\
\hline & Feijão & $10 \mathrm{~kg}$ & & $2 \mathrm{~kg}$ \\
\hline & Macarrão & 4 potes (sic) & & 0,8 pote \\
\hline \multirow{3}{*}{106 (7 ago a 5 set.1963) } & \multirow{3}{*}{$\begin{array}{c}\text { Arroz } \\
\text { Feijão } \\
\text { Macarrão } \\
\text { espaguete }\end{array}$} & $22 \mathrm{~kg}$ & \multirow[t]{3}{*}{4} & $5,5 \mathrm{~kg}$ \\
\hline & & $16 \mathrm{~kg}$ & & $4 \mathrm{~kg}$ \\
\hline & & $4 \mathrm{~kg}$ & & $1 \mathrm{~kg}$ \\
\hline \multirow{3}{*}{107 (9 set a 9 out.1963) } & Arroz & $26 \mathrm{~kg}$ & \multirow[t]{3}{*}{6} & $4,330 \mathrm{~kg}$ \\
\hline & Feijão & $11 \mathrm{~kg}$ & & $1,830 \mathrm{~kg}$ \\
\hline & Macarrão & $5 \mathrm{~kg}$ & & $830 \mathrm{~g}$ \\
\hline \multirow{4}{*}{108 (11 set a 10 out.1963) } & Arroz & $8 \mathrm{~kg}$ & \multirow[t]{4}{*}{6} & $1,330 \mathrm{~kg}$ \\
\hline & Feijão & $2 \mathrm{~kg}$ & & $330 \mathrm{~g}$ \\
\hline & Macarrão & $9 \mathrm{~kg}$ & & $1,5 \mathrm{~kg}$ \\
\hline & Macarrãozinho & 2 [pacs.?] & & 0,3 pacote \\
\hline \multirow{3}{*}{109 (11 set. a 11 out.1963) } & Arroz & $12 \mathrm{~kg}$ & \multirow[t]{3}{*}{4} & $3 \mathrm{~kg}$ \\
\hline & Feijão & $7 \mathrm{~kg}$ & & $1,750 \mathrm{~kg}$ \\
\hline & Macarrão & 4 pacotes & & 1 pacote \\
\hline \multirow{3}{*}{110 (16 set. a 16 out.1963) } & Arroz & $27 \mathrm{~kg}$ & \multirow[t]{3}{*}{5} & $5,400 \mathrm{~kg}$ \\
\hline & Feijão & $20 \mathrm{~kg}$ & & $4 \mathrm{~kg}$ \\
\hline & Macarrão & 1 pote $+2 \mathrm{~kg}$ & & $\begin{array}{l}0,2 \text { pacote e } \\
400 \mathrm{~g}\end{array}$ \\
\hline \multirow{3}{*}{111 (18 set a 17 out.1963) } & Arroz & $6 \mathrm{~kg}$ & \multirow[t]{3}{*}{5} & $1,2 \mathrm{~kg}$ \\
\hline & Feijão & $1 / 2 \mathrm{~kg}$ & & $100 \mathrm{~g}$ \\
\hline & Macarrão & 2 potes & & 0,4 pote \\
\hline \multirow{4}{*}{113 (9 out. a 8 nov.1963) } & Arroz & $10 \mathrm{~kg}$ & \multirow[t]{4}{*}{3} & $3,330 \mathrm{~kg}$ \\
\hline & $\begin{array}{l}\text { Feijão fradinho e } \\
\text { roxinho }\end{array}$ & $2 \mathrm{~kg}$ & & $670 \mathrm{~g}$ \\
\hline & Macarrão / & & & \\
\hline & $\begin{array}{l}\text { Macarrão para } \\
\text { sopa }\end{array}$ & $1 / 2 \mathrm{~kg} / 200 \mathrm{~g}$ & & $233 \mathrm{~g}$ \\
\hline \multirow{3}{*}{115 (18 out. a 18 nov.1963) } & Arroz & $10 \mathrm{~kg}$ & \multirow[t]{3}{*}{2} & $5 \mathrm{~kg}$ \\
\hline & Feijão & $2 \mathrm{~kg}$ & & $10 \mathrm{~kg}$ \\
\hline & Macarrão & $3 \mathrm{~kg}$ & & $1,5 \mathrm{~kg}$ \\
\hline \multirow{3}{*}{116 (18 out. a 18 nov.1963) } & Arroz & $10 \mathrm{~kg}$ & \multirow[t]{3}{*}{2} & $5 \mathrm{~kg}$ \\
\hline & Feijão & $2 \mathrm{~kg}$ & & $1 \mathrm{~kg}$ \\
\hline & Macarrão Adria & 2 pacotes & & 1 pacote \\
\hline \multirow{3}{*}{117 (22 out. a 21 nov.1963) } & Arroz & $26 \mathrm{~kg}$ & \multirow[t]{3}{*}{4} & $6,5 \mathrm{~kg}$ \\
\hline & Feijão & $5 \mathrm{~kg}$ & & $1,250 \mathrm{~kg}$ \\
\hline & Macarrão & 9 pacotes & & 2,24 pacotes \\
\hline \multirow{3}{*}{118 (28 out. a 27 nov.1963) } & Arroz & $35 \mathrm{~kg}$ & 8 & $4,375 \mathrm{~kg}$ \\
\hline & Feijão & 12 kg & & $1,5 \mathrm{~kg}$ \\
\hline & Macarrão & 9 pacotes & & 1,125 pacote \\
\hline
\end{tabular}




\begin{tabular}{|c|c|c|c|c|}
\hline $\mathrm{N}^{0}$ do caso e período & $\begin{array}{c}\text { Gênero } \\
\text { consumido }\end{array}$ & $\begin{array}{l}\text { Unidade e } \\
\text { quantidade }\end{array}$ & $\begin{array}{c}\text { No membros } \\
\text { família }\end{array}$ & $\begin{array}{c}\text { Consumo } \\
\text { per capita/mês }\end{array}$ \\
\hline \multirow{3}{*}{119 (29 out. a 28 nov.1963) } & Arroz & $30 \mathrm{~kg}$ & \multirow[t]{3}{*}{8} & $3,750 \mathrm{~kg}$ \\
\hline & Feijão & $13 \mathrm{~kg}$ & & $1,625 \mathrm{~kg}$ \\
\hline & Macarrão & $13 \mathrm{~kg}$ & & $1,625 \mathrm{~kg}$ \\
\hline \multirow{3}{*}{120 (30 out. a 29 nov.1963) } & Arroz & $12 \mathrm{~kg}$ & \multirow[t]{3}{*}{3} & $4 \mathrm{~kg}$ \\
\hline & Feijão & $7 \mathrm{~kg}$ & & $2,334 \mathrm{~kg}$ \\
\hline & Macarrão & $3 \mathrm{~kg}$ & & $1 \mathrm{~kg}$ \\
\hline \multirow{2}{*}{202 (5 ago a 4 set.1963) } & Arroz & $8 \mathrm{~kg}$ & \multirow[t]{2}{*}{2} & $4 \mathrm{~kg}$ \\
\hline & Macarrão Adria & $4 \mathrm{~kg}$ & & $2 \mathrm{~kg}$ \\
\hline \multirow{3}{*}{205 (01 ago. a 2 set.1963) } & Arroz & $16 \mathrm{~kg}$ & \multirow[t]{3}{*}{7} & $2,286 \mathrm{~kg}$ \\
\hline & Feijão & 9 e $1 / 2 \mathrm{~kg}$ & & $1,357 \mathrm{~kg}$ \\
\hline & Macarrão & $7 \mathrm{~kg}$ & & $1 \mathrm{~kg}$ \\
\hline \multirow{3}{*}{207 (07 ago a ? set.1963) } & Arroz & $5 \mathrm{~kg}$ & \multirow[t]{3}{*}{3} & $1,667 \mathrm{~kg}$ \\
\hline & Feijão & $6 \mathrm{~kg}$ & & $2 \mathrm{~kg}$ \\
\hline & Macarrão & $6 \mathrm{~kg}$ & & $2 \mathrm{~kg}$ \\
\hline \multirow{3}{*}{208 (13 ago. a 8 set.1963) } & Arroz & $15 \mathrm{~kg}$ & \multirow[t]{3}{*}{3} & $5 \mathrm{~kg}$ \\
\hline & Feijão & $8 \mathrm{~kg}$ & & $2,667 \mathrm{~kg}$ \\
\hline & Macarrão & $3 \mathrm{~kg}$ & & $1 \mathrm{~kg}$ \\
\hline \multirow{3}{*}{209 (16 ago a 12 set.1963) } & Arroz & $36 \mathrm{~kg}$ & \multirow[t]{3}{*}{6} & $6 \mathrm{~kg}$ \\
\hline & Feijão & $10 \mathrm{~kg}$ & & $1,667 \mathrm{~kg}$ \\
\hline & Macarrão & $3 \mathrm{~kg}$ & & $500 \mathrm{~g}$ \\
\hline \multirow{3}{*}{213 (20 set. a 21 out.1963) } & Arroz & $15 \mathrm{~kg}$ & \multirow[t]{3}{*}{5} & $3 \mathrm{~kg}$ \\
\hline & Feijão & $10 \mathrm{~kg}$ & & $2 \mathrm{~kg}$ \\
\hline & Macarrão & $3 \mathrm{~kg}$ & & $600 \mathrm{~g}$ \\
\hline \multirow{3}{*}{214 (25 set. a 25 out.1963) } & Arroz & $18 \mathrm{~kg}$ & \multirow[t]{3}{*}{5} & $3,6 \mathrm{~kg}$ \\
\hline & Feijão & $4 \mathrm{~kg}$ & & $800 \mathrm{~g}$ \\
\hline & Macarrão & $3 \mathrm{~kg}$ & & $600 \mathrm{~g}$ \\
\hline \multirow{3}{*}{215 (01 a 31 out. 1963) } & Arroz & $5 \mathrm{~kg}$ & \multirow[t]{3}{*}{$\mathrm{n} /$ consta } & - \\
\hline & Feijão & $4 \mathrm{~kg}$ & & - \\
\hline & Macarrão & $2 \mathrm{~kg}$ & & - \\
\hline \multirow{3}{*}{216 (03 out. a 03 nov.1963) } & Arroz & $20 \mathrm{~kg}$ & \multirow[t]{3}{*}{4} & $5 \mathrm{~kg}$ \\
\hline & Feijão & $11 \mathrm{~kg}$ & & $2,750 \mathrm{~kg}$ \\
\hline & Macarrão & $2 \mathrm{~kg}$ & & $500 \mathrm{~g}$ \\
\hline \multirow{3}{*}{217 (7 out. a 6 nov.1963) } & Arroz & $30 \mathrm{~kg}$ & 6 & $5 \mathrm{~kg}$ \\
\hline & Feijão & $10 \mathrm{~kg}$ & & $1,667 \mathrm{~kg}$ \\
\hline & Macarrão & $2 \mathrm{~kg}$ & & $334 \mathrm{~g}$ \\
\hline 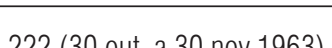 & Arroz & $5 \mathrm{~kg}$ & 3 & $1,667 \mathrm{~kg}$ \\
\hline 222 (30 out. a 30 nov. 1963) & Macarrão & 3 pacotes & & 1 pacote \\
\hline & Arroz & $8 \mathrm{~kg}$ & 4 & $2 \mathrm{~kg}$ \\
\hline 301 (06 ago a ob set.1963) & Feijão & $5 \mathrm{~kg}$ & & $1,250 \mathrm{~kg}$ \\
\hline & Arroz & $20 \mathrm{~kg}$ & 11 & $1,818 \mathrm{~kg}$ \\
\hline 302 (1 ago. a 31 set.1963) & Feijão & $11 \mathrm{~kg}$ & & $1 \mathrm{~kg}$ \\
\hline & Macarrão & 2 pacotes & & 0,18 pacote \\
\hline 303 (05 an a 04 set 1963$)$ & Arroz & $20 \mathrm{~kg}$ & 6 & $3,333 \mathrm{~kg}$ \\
\hline & Feijão & $4 \mathrm{~kg}$ & & $666 \mathrm{~g}$ \\
\hline & Arroz & $25 \mathrm{~kg}$ & 7 & $3,570 \mathrm{~kg}$ \\
\hline 304 (09 ago a ? 1963) & Feijão & $13 \mathrm{~kg}$ & & $1,857 \mathrm{~kg}$ \\
\hline & Macarrão & $3 \mathrm{~kg}$ & & $429 \mathrm{~g}$ \\
\hline
\end{tabular}


Além do macarrão, outros poucos itens industrializados compunham a dieta dos trabalhadores paulistanos em 1937. Os mais óbvios, ainda que hoje quase não pensemos neles como bens industriais ao consumi-los, eram o pão (de trigo e, em poucos casos, de centeio ou integral), o leite (engarrafado ou em pó) e seus derivados (manteiga e queijo), o café torrado e moído, farinhas e açúcar.

A estes itens básicos, somavam-se poucos outros, como o vinho (mencionado em dois casos), a banha (seis casos), aguardente (um caso), o vinagre (cinco casos), chás (incluindo preto e mate, em três casos), mortadela (quatro casos), óleo e azeite (seis casos), refrigerante (um caso de consumo de guaraná) e a massa ou extrato de tomate (três casos). Quanto a este último produto, o apelo da propaganda vinculavase à promessa de rapidez no preparo, entre outras vantagens ${ }^{28}$ - e seu consumo entre famílias de trabalhadores já em 1937, ampliado na pesquisa de 1963, demonstra a ressonância da propaganda e a efetiva utilidade do produto entre o público de menor renda e com menos tempo para o preparo de molhos. ${ }^{29}$

Vinte e seis anos depois, os produtos industrializados tornaram-se muito mais comuns, e as marcas passaram a ser mencionadas com maior frequência. Primeiramente, vejamos o caso do pão. Um sinal da sofisticação das padarias pode ser notado a partir da nomenclatura utilizada para definir o produto. Na PPV Lowrie, as famílias anotavam nas cadernetas de consumo simplesmente a palavra "pão" (em três casos seguida dos adjetivos descritores "de centeio", "integral" ou "doce") e as quantidades, definidas em quilogramas ou unidades cujo peso não foi indicado. Já na PPV Pagano, o pão continuou a ser comprado em unidades cuja especificidade vinha anotada: eram principalmente filões ou bengalas, pães mais compridos e próprios para serem cortados em fatias divididas entre os membros da família, com eventuais disputas domésticas pelos bicos - mais crocantes e com menos miolo. A partir dos indícios representados pelas cadernetas, é difícil saber se os filões não eram produzidos na época da primeira PPV ou se o mesmo tipo de pão que já era consumido anteriormente apenas ganhou novos designativos populares.

O leite continuou a ser consumido in natura ou em pó, este último industrializado a partir da descoberta do método da desidratação em 1911 e comercializado no Brasil desde 1923. Essa descoberta, juntamente com o processo mais geral de industrialização e da urbanização e o novo papel da mulher no mercado de trabalho "foram os principais responsáveis pela

28 Cf. OLIVEIRA, Débora Santos de Souza. A transmissão do conhecimento culinário no Brasil urbano do século XX. São Paulo: FFLCH/USP, 2010, p.168. (Dissertação de Mestrado).

29 Quatro dentre oito cadernetas da PPV Lowrie e 23 dentre as 34 cadernetas da PPV Pagano assinalaram o consumo de massa ou extrato de tomate. 
diminuição do aleitamento materno no século XX, com repercussões desastrosas para a saúde das crianças e, também, para as mulheres". ${ }^{30} \mathrm{Na}$ década de 1960, as cadernetas permitem apontar um aumento no consumo e também a menção às marcas - neste caso, Glória e Ninho, sendo o último fabricado com esse nome a partir de 1944. ${ }^{31}$

Os queijos, mencionados em 1937 apenas pelo nome genérico, também ganharam espaço na mesa dos trabalhadores em São Paulo em 1963. Além do genérico, apareciam nas formas "ralado", "para ralar", "duro" e "parmesão" - certamente para acompanhar as massas, como os italianos faziam havia séculos $-{ }^{32}$ fresco e minas - consumidos com pão. Genericamente também era denominada a farinha, que suponho seja a de trigo, em 1937, sendo que em 1963 era possível saber se se tratava de farinha de trigo, de mandioca, de milho ou de rosca, fruto da diversificação industrial e de concessões ao gosto dos consumidores.

Com o café torrado e moído, a menção às marcas foi o processo mais evidente a diferenciar o consumo no intervalo entre as duas pesquisas. Se anteriormente a marca não importava ou não remetia à qualidade do produto, na PPV Pagano os consumidores revelavam suas preferências e possibilidades de compra: Caboclo (de 1930), ${ }^{33}$ Tiradentes (1915), ${ }^{34}$ Seleto e Americano foram as marcas assinaladas.

No quesito "gorduras", a banha aparece nos dois momentos pesquisados. A julgar pelas quantidades marcadas - entre um e sete quilogramas mensais - pode-se imaginar que o produto era utilizado em frituras e especular acerca da longevidade de um método de conservação de carnes cozidas ou defumadas, sobretudo naquelas famílias que tinham por hábito esse tipo de conserva e/ou que não possuíam geladeiras com termostatos eficientes, bem como ligação à rede de distribuição de energia elétrica.

$\mathrm{O}$ azeite foi mencionado nas duas pesquisas, com destaque para a marca Maria, citada em um lar dos anos 1960. ${ }^{35}$ Tratava-se de óleo misto, com pequeno percentual de azeite de oliva - ingrediente tido como pilar da cozinha mediterrânica. Neste caso, o hábito arraigado pode ter se adaptado à condição de renda das famílias e à oferta de produto - embora "azeite d'oliveira puríssimo" fosse vendido na cidade havia décadas ${ }^{36}$ Azeite era um produto caro também na Europa, e seu uso para frituras e como tempero

30 VINAGRE, Roberto Diniz; DINIZ, Edna Maria A. e VAZ, Flávio Adolfo Costa.Leite humano: um pouco de sua história. Pediatria, São Paulo, v.23, n.4, p.342, 2001.

31 Cf. http://www.nestle.com.br/site/anestle/historia.aspx (acesso em 25 abr.2011). Ver também OLIVEIRA, Débora Santos de Souza. A transmissão do conhecimento culinário no Brasil urbano do século XX, p. 96.

32 No início dos tempos modernos, o consumo de queijo sofrera queda, "encontrando-se praticamente limitado a uma presença quase irrecusável na cobertura das massas italianas e, de um modo geral, ralado". AGUILERA, César. História da alimentação mediterrânica. Lisboa: Terramar, 2001, p.128.

33 Cf. http://www.cafecaboclo.com.br/a-marca.aspx (acesso em 25 abr.2011).

34 Cf. http://www.cafetiradentesaltinopolis.com.br/brasil.htm (acesso em 25 abr.2011).

35 PPV Pagano, caso 208, 13 ago. a 8 set.1963.

36 Ver anúncio da marca Bertolli, "o preferido", em O Cruzeiro, 10 jan.1931, nº 10, p.6. 
de verduras e legumes em saladas conjugava-se ao da banha de porco no cozimento de alimentos desde muito tempo. ${ }^{37}$

O óleo para frituras, que em 1937 aparecia apenas pela designação genérica (não sabemos se de milho ou de soja, os mais comuns), também ganhou detalhamento nos tipos e nas marcas em 1963: Sá, Mindol, Delícia e Salada (fabricado desde 1929), ${ }^{38}$ além dos óleos de algodão e de amendoim, sem referência às marcas, foram mencionados. Margarina, que não era mencionada na primeira pesquisa, surge em 1963 com referências às marcas Saúde (fabricada a partir dos anos 1950), ${ }^{39}$ Claybom e Delícia (lançadas no Brasil em 1948), ${ }^{40}$ além da Matarazzo.

Nas instruções que os pesquisadores das PPVs davam às mulheres para preencherem as cadernetas, não há nenhuma menção à necessidade de assinalar as marcas dos produtos consumidos. Considerando que essas instruções foram praticamente as mesmas e que a metodologia das pesquisas não se alterou entre 1937 e 1963, ${ }^{41}$ a menção mais constante às marcas deve ser entendida como fruto da diversificação industrial e da penetração da propaganda nos meios populares. As famílias consumiam chocolates, mas uma delas comprou Bis, fabricado desde 1942; consumiam "massa" (também chamada de "extrato" ou "purê") de tomate, e citaram a marca Elefante, "o melhor e mais procurado" e "o preferido em todo o Brasil", 42 nos termos da propaganda. Leite condensado das marcas Glória e Moça - este último importado desde 1921 e fabricado no Brasil desde $1930^{43}$-e fermento em pó Royal - importado desde 1923 e produzido no Brasil a partir de $1934^{44}$ - já estavam disponíveis na época da PPV Lowrie, mas nem os produtos nem as marcas foram anotados nas cadernetas remanescentes.

O sal de cozinha, produto disponível havia tempos, ganhara maior visibilidade comercial em meados da década de 1950, quando decreto federal tornou obrigatória sua iodação, para combater o bócio endêmico. ${ }^{45}$

37 AGUILERA, César. História da alimentação mediterrânica, p.129 e ss.

38 Cf. http://www.salada.com.br/novosalada/Produtos/OleoCompostoSalada.aspx (acesso em 25 abr.2011). Em anúncio da década de 1940, a marca vendia-se como "o famoso azeite". Ver: Viver! Mensário de força, saúde e beleza, v.4, n.47, p.1, 1942.

39 Cf. http://blcamargo.blogspot.com/2009/07/imagens-alimentobebida-margarina-saude.html (acesso em 25 abr.2011).

40 Cf. http://www.unilever.com.br/Images/HISTORIA DA UNILEVER FINAL tcm95-112364.pdf\#search=\%22claybom \%22 (acesso em 25 abr.2011).

41 Sobre os métodos e instrumentos de pesquisa acerca do consumo alimentar em perspectiva histórica, ver VASCONCELOS, Francisco de Assis Guedes de. Tendências históricas dos estudos dietéticos no Brasil. História, Ciências, Saúde: Manguinhos, Rio de Janeiro, v.14, n.1, mar.2007. Disponível em http://www.scielo.br/scielo. php?script=sci_arttext\&pid=S0104-59702007000100010\&lng=pt\&nrm=iso (acesso em 30 maio 2011).

42 Cf. anúncio em O Cruzeiro, 10 jan.1931, p.6 e 25 fev.1950, p.61.

43 Cf. http://www.nestle.com.br/site/anestle/historia.aspx (acesso em 26 abr.2011). Para uma história desse produto, consultar OLIVEIRA, A transmissão, p.82 e ss.

44 Cf. http://www.mundodasmarcas.blogspot.com/2006/08/fermento-royal-um-cone-da-culinria.html (acesso em 26 abr.2011).

45 Decreto $n^{\circ}$ 39.314, de 17 de agosto de 1956: delimita-se as áreas bocígenas do Brasil, dispõe sobre o uso do sal iodetado e dá outras providências. Disponível em http://www6.senado.gov.br/legislacao/ListaPublicacoes.action ?id=171092\&tipoDocumento=DEC\&tipoTexto=PUB (acesso em 26 abr.2011). 
O da marca Cisne, fabricada desde 1953, ${ }^{46}$ foi o único citado (em seis casos) entre os consumidores na PPV Pagano. No rol das marcas referentes a outros produtos, também foram citadas as do amido de milho Maizena, complemento alimentar Vic Maltema, achocolatado Nescau, ${ }^{47}$ aveia Quaker, ${ }^{48}$ bolo Pulman, ${ }^{49}$ preparado para massa de bolo Santista, ervilhas Etti e Jurema e sorvete Kibon, indústria que iniciou suas atividades no Brasil em 1942. A linha de montagem brasileira da fábrica de sorvetes foi instalada no Rio de Janeiro a partir da desmontagem da fabrica de Xangai, para proteger o capital do estadunidense Ulysses Severin Harkson, quando da invasão japonesa na China. ${ }^{50}$

No âmbito das bebidas, as cadernetas das PPVs também permitem vislumbrar timidamente as preferências populares. Em 1937, o consumo doméstico declarado limitava-se à pinga (1 litro em apenas um caso) e ao vinho (2 litros, divididos em dois casos). Certamente seria ingênuo se acreditássemos que as famílias pesquisadas eram quase abstêmias: ocorre que o consumo de bebidas alcoólicas podia ser entendido como exterior ao consumo alimentar e os gastos com elas poderiam representar distorções na pesquisa do padrão de vida.

Isso sem contar que, por resguardo da privacidade, muitas famílias talvez optassem por não declarar a quantidade realmente consumida, ou mesmo privilegiar o consumo de álcool fora de casa, em sociabilidade mais ampla. Daisy de Camargo inventariou bebidas e lugares populares do consumo e produção delas na São Paulo entre a segunda metade do século XIX e a década de 1920, tratando do funcionamento de tascas e entreveros envolvendo seus frequentadores e a polícia, além de elaborar uma "cartografia ordinária" das regiões onde se instalava esse comércio no centro da cidade..$^{51}$ Ampliar esse estudo para outras regiões e temporalidades no século $X X$ traria uma contribuição relevante para a história do cotidiano entre os populares durante a metropolização de São Paulo.

No início da década de 1960, o consumo doméstico de bebidas alcoólicas sofreu um impacto semelhante ao dos demais produtos alimentícios industrializados. Vinho e pinga continuaram a ser mencionados genericamente, ao lado de destilados como vermout e das marcas Cinzano e Martini. No caso das cervejas, Brahma, Caracu e Malzbier foram as marcas mencionadas. As duas últimas, cervejas pretas, eram tidas, no imaginário popular,

46 Cf. http://www.salcisne.com.br/institucional.html (acesso em 26 abr.2011).

47 Desenvolvido no Brasil e comercializado desde 1932, cf. http://www.mundodasmarcas.blogspot.com/2006/05/ nescau-energia-que-d-gosto.html (acesso em 26 abr.2011).

48 Produzida no Brasil desde 1952, cf. http://www.mundodasmarcas.blogspot.com/2006/05/quaker-oats-alimentaosaudvel.html (acesso em 26 abr.2011).

49 Comercializado desde 1953, Cf. http://www.mundodasmarcas. blogspot.com/2006/06/pullman-o-po-gostoso.html (acesso em 26 abr.2011)

50 C. CAVALCANTI, Pedro \& CHAGAS, Carmo. História da embalagem no Brasil. São Paulo: Grifo, 2005, p.136.

51 Cf. CAMARGO, Daisy de. Alegrias engarrafadas: os alcoóis e a embriaguez na cidade de São Paulo no final do século XIX e começo do XX. Assis: UNESP, 2010. (História, Tese de Doutorado). 
como fortificantes para grávidas e nutrizes. Espertamente, esse imaginário foi apropriado e estimulado pelos publicitários, que divulgavam Malzbier na mídia impressa com um desenho de pai, mãe e criança observando a garrafa do produto e a legenda "a cerveja para todas as idades" ${ }^{52}$ As grávidas das classes populares eram dadas à "malfadada cerveja preta domingueira", para irritação dos intelectuais que defendiam a racionalização do consumo alimentar entre os populares desde pelo menos o Estado Novo. ${ }^{53}$

Mas o consumo de bebidas nos lares não se restringia aos alcoóis. Os refrigerantes, embora fabricados desde fins do século XIX - como o guaraná Antarctica, de 1921 -, não apareceram na lista de itens consumidos nas cadernetas remanescentes de 1937. A palavra "refrigerante" também não apareceu nas 34 cadernetas restante do ano de 1963, mas sim as marcas e tipos guaraná (13 casos), Coca Cola (5 casos) e tubaína.

Os chás, genéricos ou nas variedades preto e mate, aparecerem em 3 dos oito casos restantes da PPV Lowrie. Na PPV Pagano, o mate supera as menções ao chá preto, sendo mencionada a marca Leão. ${ }^{54}$

\section{Considerações finais}

Quais seriam as condições de abastecimento existentes em São Paulo nos dois períodos assinalados neste estudo? Nessa altura, tudo o que posso dizer é que se tratava de condições muito diferentes, dos pontos de vista da produção de alimentos, da organização empresarial, da distribuição, da visibilidade do poder público como agente regulamentador e, sobretudo, das práticas alimentares dos consumidores. A vereda aberta por uma historiografia social como a que Maria Luiza Ferreira de Oliveira fez para a cidade da segunda metade do século XIX, entendendo que "a vida comercial da cidade concorria mesmo para formar sua identidade", está em busca de outros que a alarguem..$^{55}$

Propagandas, embalagens, artes gráficas e indícios textuais preservados a partir do recolhimento documental aos arquivos históricos são fontes importantes para se estudar a alimentação entre grupos sociais ou concentrações populacionais dos mais variados tamanhos e composições. Neste caso, privilegiei a cidade de São Paulo nos anos 1930 e 1960, mas outros estudos são possíveis, sob a abordagem que dei aqui ou outras. Além desses vestígios materiais, é preciso considerar a perspectiva das tradições nacionais ou regionais e as transformações ocorridas no processo histórico que levariam à reinvenção dessas mesmas tradições, para podermos

52 Viver! Mensário de força, saúde e beleza, v.2, n.20, p.3, 2 mar.1940.

53 BOTELHO, Thalino. Acesso à alimentação racional. 2aaed. Rio de Janeiro: s/e, 1955, p.134-135.

54 PPV Pagano, casos 104 e 208.

55 OLIVEIRA, Maria Luiza Ferreira de. Entre a casa e o armazém: relações sociais e experiência da urbanização (São Paulo, 1850-1900). São Paulo: Alameda, 2005, p.211. 
analisar as práticas alimentares como partes constituintes do patrimônio histórico, ampliando a própria concepção deste último.

Sabemos ser possível o estudo e a exposição dos apetrechos de cozinha como objetos museológicos e históricos, sendo o Museu do Pão (em llópolis, Rio Grande do Sul) e a área temática de ofícios de cozinha do Museu de Artes e Ofícios (Belo Horizonte) bons exemplos disso. Em espaços expositivos, a antiguidade da tradição costuma ser um grande atrativo para pesquisadores e também para o público não-especializado, sendo talvez necessário pensar-se em espaços que consigam dar conta das transformações e incorporar processos mais recentes. Ao mesmo tempo, são relevantes as relações entre culinária e memória, sobretudo no âmbito familiar.

Por tudo isso, tornar a alimentação um tema de interesse mais amplo, extravasando a privacidade e incluindo grupos sociais mais vastos, pode nos levar a uma melhor compreensão das transformações das práticas alimentares como expressão da dinâmica da vida cotidiana. Tais transformações são marcadas, eventualmente, por bruscas rupturas ou lentas alterações, estas últimas às vezes imperceptíveis para aqueles que vivem o dia a dia e não veem a si mesmos como sujeitos históricos. A própria concepção de patrimônio histórico, ou melhor, a atuação dos órgãos patrimoniais, poderia ser revista à luz da história do cotidiano e da incorporação de temporalidades mais recentes às políticas de preservação, tendo em vista a aceleração das mudanças nos dias que correm. Encarada em perspectiva histórica, a alimentação, pelos vestígios materiais e imateriais que deixa, presta-se a uma reflexão ampla acerca dos costumes e práticas sociais. 